\title{
SPL REMS Stakeholder Terminology
}

National Cancer Institute

\section{Source}

National Cancer Institute. SPL REMS Stakeholder Terminology. NCI Thesaurus. Code C128493.

Terminology used in the framework of REMS SPL data to represent stakeholders who participate in the REMS based on the role they play in the medication use and distribution process. 